\title{
Desenvolvimento de Cordia trichotoma em função da adubação, em sistema silvipastoril no Sudoeste do Paraná-Brasil ${ }^{1}$
}

\author{
Priscyla Vanessa Antonelli² ${ }^{2}$ Eleandro José Brun ${ }^{3}$; Marcielli Aparecida Borges dos Santos ${ }^{4}$; Laercio \\ Ricardo Sartor ${ }^{5}$; Flávia Gizele Konig Brun ${ }^{6}$
}

Resumo: O estudo teve o objetivo principal de analisar o desenvolvimento inicial do louro-pardo (Cordia trichotoma (Vell.) Arrab. ex Steud.), implantado sob diferentes níveis de adubação, em sistema silvipastoril. Para tanto, realizou-se o consórcio de louro-pardo com capim Panicum maximum cv. aruana na Universidade Tecnológica Federal do Paraná - Câmpus Dois Vizinhos. Foram alocadas 4 linhas duplas em intervalo de $10 \mathrm{~m}$ com espaçamento de $2 \mathrm{~m}$ x 1,5 m nessas linhas. O solo foi preparado com escarificador até uma profundidade de $30 \mathrm{~cm}$. No plantio, juntamente com as mudas foram adicionados 250 $\mathrm{mL} /$ planta de uma solução de hidrogel. Com o propósito de avaliar a importância da adubação com NPK no sistema implantado, esta foi testada em quatro níveis diferentes (tratamentos): T1 (sem adubação), T2 (o recomendado), T3 ( 2 x recomendado) e T4 (3 x recomendado). Para avaliação do estudo, mediram-se a altura das plantas, diâmetros do colo e dois diâmetros de copa equidistantes, como também se realizaram avaliações qualitativas de vigor, conforme parâmetros de sanidade, ocorrência de pragas ou doenças, crescimento, aspecto visual geral das folhas e tronco, estresse nutricional e hídrico. Os dados obtidos foram analisados estatisticamente através do software Assistat v. 7.6 Beta. Os resultados apontaram um crescimento relativo (CR\%) médio de 374,2\% em diâmetro do colo, 278,3\% em altura e 1351,1\% em área de copa, nos 10 meses avaliados. O vigor das plantas não foi influenciado pela adubação, pois independente da dose, houve redução significativa na qualidade das plantas em função de ocorrência de uma bacteriose e a coincidência com o período de inverno, por se tratar de uma planta caducifólia. Com base nos resultados de crescimento obtidos até a idade avaliada, recomenda-se o uso de $192 \mathrm{~g} /$ planta de NPK, na formulação testada, para o louro-pardo.

Palavras - chave: Sistemas agroflorestais; Louro-pardo; Nutrição florestal.

\section{Cordia trichotoma development in function of the fertilization in silvipastoral system in Southwest region of Paraná-Brazil}

\begin{abstract}
This study aimed mainly to analyze the initial development of the louro-pardo (Cordia trichotoma (Vell.) Arrab. ex Steud.), planted at different levels of fertilization in silvopastoral system. Therefore, was made a louro-pardo consortium with grass Panicum maximum cv. aruana at the Universidade Tecnologica Federal do Paraná - Campus Dois Vizinhos. Were allocated 4 double lines in the range of $10 \mathrm{~m}$ with spacing of $2.0 \mathrm{~m} \times 1.5 \mathrm{~m}$ these lines. The soil was prepared with a scarifier up until a depth of $30 \mathrm{~cm}$. In the planting, jointly the seedlings were added $250 \mathrm{ml} / \mathrm{plant}$ of a hydrogel solution. In order to assess the importance of NPK fertilization on the system, this was tested at four different levels (treatments): T1 (without fertilization), T2 (recommended), T3 (twice the recommended) and T4 (triple the recommended). To evaluate the study, plant height measurements were made, stem diameter and two equidistant crown diameters, also were made qualitative evaluations of vigor, according health parameters, occurrence of pests or diseases, growth, overall visual appearance of the leaves and stem, nutrition and water stress. Data were statistically analyzed by software Assistat v. 7.6 Beta. The results showed a mean relative growth of $374.2 \%$ for the stem diameter, $278.3 \%$ for height and $1351.1 \%$ for crown area in the 10 months evaluated. The plant vigor was not influenced by the fertilizer levels, as independent of the tested treatment, there was significant reduction in the quality of seedlings due to the occurrence of bacteria and the coincidence with the winter period, because it is a deciduous plant. According to the study, can be recommended the dose of $192 \mathrm{~g} \mathrm{plant}^{-1}$ (T4) of NPK with the tested formulation to louro-pardo.
\end{abstract}

Keywords: Agroforestry systems; Louro-pardo; Forest nutrition.

\footnotetext{
${ }^{1}$ Recebido em 08.08.2015 e aceito para publicação como artigo científico em 04.11.2015.

${ }^{2}$ Engenheira Florestal, e Ambiental - Sulgeo Serviços Ambientais. E-mail: <eng.priscyla@ hotmail.com>.

${ }^{3}$ Engenheiro Florestal Dr., Professor da UTFPR Campus Dois Vizinhos. E-mail: <eleandrobrun@utfpr.edu.br>.

${ }^{4}$ Engenheira Florestal, Mestranda do Programa de Pós-graduação em Ciência do Solo do Centro de Ciências Agroveterinárias da Universidade do Estado de Santa Catarina (CAV-UDESC). E-mail: <eng.marcielli@ outlook.com>.

${ }^{5}$ Engenheiro Agrônomo, Dr., Professor da UTFPR Campus Dois Vizinhos. E-mail: <laerciosartor@utfpr.edu.br>.

${ }^{6}$ Engenheira Florestal Dra., Professora da UTFPR Campus Dois Vizinhos. E-mail: <flaviag@utfpr.edu.br>.
} 


\section{Introdução}

Sistema silvipastoril (SSP) é uma das modalidades da Integração Lavoura Pecuária Floresta (ILPF), que consiste em combinar a produção florestal com a pecuária dentro de uma mesma área, de forma que hajam benefícios para ambas as atividades (CARVALHO, 2001). Este sistema pode ser adotado por produtores rurais, independentemente do tamanho de suas propriedades, sendo que o sucesso se encontra no planejamento adequado às necessidades de cada área.

Além do aumento da produtividade, a combinação entre floresta e pecuária traz benefícios ecológicos como a preservação das florestas, a recuperação de áreas degradadas, melhora no microclima local, aumento do sequestro de carbono e expansão da produção (BALBINO et al., 2011). Somam-se a esses benefícios, ainda, a fixação do homem no campo, o enriquecimento do solo e a madeira como um produto extra, viabilizando economicamente o consórcio através do uso múltiplo dos espaços existentes na propriedade rural.

Radomski et al. (2012) salientaram que a espécie florestal nativa Cordia trichotoma (Vell.) Arrab. ex Steud., conhecida como Louropardo, mesmo apresentando crescimento considerado de lento a moderado, apresenta potencial para uso em sistemas de produção integrados, inclusive na arborização de pastagens, em função de sua madeira ser de utilização para finalidades consideradas nobres.

$\mathrm{O}$ uso de espécies florestais nativas em sistemas integrados de produção é algo ainda pouco comum no Brasil, muito em função do crescimento relativamente mais lento da maioria dessas espécies e do pouco conhecimento acumulado sobre sua silvicultura. Porém, pesquisas vêm sendo realizadas e tem demonstrado que o potencial de crescimento e fornecimento de madeiras nobres nesses sistemas é aspecto promissor.

Sabe-se também que o crescimento das espécies florestais nativas pode ser acelerado, ou pelo menos melhorado, com o uso de adubação mineral. Essa alternativa, além de acelerar o crescimento, vem contribuir para o desenvolvimento de plantas mais saudáveis, diminuindo a mortalidade e aplicação de tratos culturais, remetendo a uma diminuição de custos.

Neste sentido, o presente trabalho teve como objetivo principal analisar o desenvolvimento inicial do Louro-pardo (Cordia trichotoma (Vell.) Arrab. ex Steud.), implantado sob diferentes níveis de adubação, em sistema silvipastoril, em área experimental na região Sudoeste do Paraná.

\section{Material e métodos}

Caracterização da área em estudo

O experimento foi realizado na Estação Experimental da Universidade Tecnológica Federal do Paraná, Câmpus Dois Vizinhos. Dois Vizinhos localiza-se em uma região subtropical úmida cujo clima, segundo a classificação de Koeppen, é o Cfa (ALVARES et al., 2013). De acordo com as cartas climáticas do Paraná, apresenta umidade relativa anual em torno de $75 \%$ e temperatura média no trimestre mais quente (dezembro, janeiro e fevereiro) de 25 a 26 ${ }^{\circ} \mathrm{C}$ e no trimestre mais frio (junho, julho e agosto) de 14 a $15{ }^{\circ} \mathrm{C}$, com temperatura média anual de $19{ }^{\circ} \mathrm{C}$; a precipitação média anual fica em torno de 1.800 a $2.000 \mathrm{~mm}$ (IAPAR, 2000).

Quanto à vegetação, Dois Vizinhos apresenta fragmentos de floresta nativa, a qual classificase como área de transição entre dois tipos florestais importantes, a Floresta Ombrófila Mista e a Floresta Estacional Semidecidual (IBGE, 2004).

No local de estudo o solo foi classificado como Latossolo Vermelho Distroférrico típico (EMBRAPA, 2014), com a área experimental estando sob cobertura de pastagem Panicum maximum cv. Aruana implantada com a finalidade de pastejo para ovinos.

Implantação do experimento

A área experimental possui $2.160 \mathrm{~m}^{2}$, onde 
implantaram-se 4 linhas duplas, num intervalo de 10,0 metros entre elas e espaçamento de 2,0 $\mathrm{m} \times 1,5 \mathrm{~m}$ nas linhas. Em cada conjunto de linhas duplas, o solo foi preparado com uso de escarificador tratorizado de cinco hastes, até uma profundidade aproximada de $30,0 \mathrm{~cm}$.

A introdução da espécie florestal ocorreu em setembro de 2013, com mudas produzidas em tubetes, originárias de sementes coletadas em cerca de 30 matrizes superiores selecionadas em ACS (Área de Coleta de Sementes) na região Oeste e Sudoeste do Paraná. O porte das mudas era, em média, de $20 \mathrm{~cm}$ de altura. No momento do plantio das 176 mudas, na cova, adicionou-se $250 \mathrm{ml} \mathrm{planta}^{-1}$ de uma solução de hidrogel (concentração de 0,2\%) para aumentar a hidratação das raízes e o consequente pegamento das mudas.

Desde o preparo da área, de forma rotineira, foi realizado o controle de formigas cortadeiras, utilizando-se iscas granuladas a base de Fipronil $(0,03 \mathrm{~g} / \mathrm{kg})$, que foram lançadas ao lado dos carreiros e olheiros das formigas numa dosagem de $10 \mathrm{~g} / \mathrm{m}^{2}$ e, nos momentos mais críticos da implantação, para evitar maiores danos às mudas, realizou-se a pulverização destas com formicida líquido também a base de Fipronil (concentração de 20\%) com uma dosagem de 80 $\mathrm{mL} \mathrm{ha}^{-1}$ (40 mL/10 L água).

Para o controle de plantas daninhas, durante os primeiros meses, fez-se coroamento no entorno das mudas com capina manual num raio de um metro e, nas entrelinhas, realizou-se roçada tratorizada.

O arranjo experimental implantado consistiu em um delineamento blocos ao acaso, onde cada linha dupla (2 linhas de 22 plantas cada) consistiu em um bloco, totalizando 4 blocos/tratamento, onde foram aplicados os 4 tratamentos em 10 plantas em cada bloco, ficando as 4 plantas das extremidades de cada linha dupla como bordadura.

\section{Adubação}

Com o propósito de avaliar a importância da adubação mineral para o louro-pardo no sistema implantado, esta foi testada em quatro níveis (tratamentos): sem adubação (T1), o recomendado pela análise (T2), o dobro (T3) e o triplo (T4) do recomendado. O cálculo da dose recomendada de adubação foi efetuado com base na recomendação oficial para espécies de Eucalipto, descritos no Manual de Adubação e de Calagem para os Estados do Rio Grande do Sul e de Santa Catarina (SBCS-CQFS, 2004), pela ausência de recomendação oficial para o louro-pardo na literatura técnico-científica.

De acordo com a análise de solo realizada para a área, a recomendação de adubação de base foi de $30 \mathrm{~kg} \mathrm{ha}^{-1}$ de $\mathrm{P}_{2} \mathrm{O}_{5}, 20 \mathrm{~kg} \mathrm{ha}^{-1}$ de $\mathrm{K}_{2} \mathrm{O}$ e 50 $\mathrm{kg} \mathrm{ha}{ }^{-1}$ de $\mathrm{N}$. Os adubos utilizados foram Superfosfato triplo $\left(40 \% \mathrm{P}_{2} \mathrm{O}_{5}\right)$, Cloreto de potássio $\left(60 \% \mathrm{~K}_{2} \mathrm{O}\right)$ e Ureia $(45 \% \mathrm{~N})$ (Tabela 1$)$. A adubação com NPK foi feita em covetas laterais no segundo mês após o plantio, quando as plantas já estavam estabelecidas quanto ao seu pegamento (plantio e replantio) e com sistema radicular já em desenvolvimento, tornando mais eficiente a absorção dos nutrientes da adubação.

Tabela 1: Dosagem de adubo utilizado por planta, de acordo com os tratamentos (T1: sem adubação, T2: dosagem recomendada, T3: duas vezes a dosagem recomendada e T4: três vezes a dosagem recomendada).

Table 1: Dosage fertilizer used by plant, according to the treatments (T1: unfertilized, T2: recommended dosage; T3: twice the recommended dosage and T4: three times the recommended dosage).

\begin{tabular}{cccc}
\hline \multirow{2}{*}{ Tratamento } & \multicolumn{3}{c}{ Doses $\left(\mathbf{g ~ p l a n t a}^{-1}\right)$} \\
\cline { 2 - 4 } & $\mathbf{N}$ & $\mathbf{P}_{\mathbf{2}} \mathbf{O}_{\mathbf{5}}$ & $\mathbf{K}_{\mathbf{2}} \mathbf{O}$ \\
\hline 1 & 0 & 0 & 0 \\
2 & 33 & 22 & 9 \\
3 & 66 & 44 & 18 \\
4 & 99 & 66 & 27 \\
\hline
\end{tabular}


Avaliação da espécie arbórea

Após dois meses da implantação, quando as mudas com pegamento já estavam estabelecidas, fez-se a quantificação da sobrevivência geral das mesmas e, como ocorreu índice de mortalidade superior a $10 \%$, efetuou-se o replantio.

No decorrer do experimento, com base em indicadores estabelecidos para este trabalho, foram feitas avaliações qualitativas referentes ao vigor, anotando-se em planilha os seguintes critérios: alto vigor (1); médio vigor (2) e baixo vigor (3), conforme avaliação visual de parâmetros de sanidade, ocorrência de pragas ou doenças, aspecto visual geral das folhas e tronco, estresse nutricional e hídrico, classificando-se a ausência ou presença mínima dos itens citados como alto vigor, ocorrência mediana como médio vigor e alta ocorrência dos fatores citados, podendo comprometer a sobrevivência das mudas, como baixo vigor.

As avaliações quantitativas quanto ao crescimento em altura, diâmetros do colo e diâmetro de copa foram realizadas aos 3, 5, 6, 7, 8 e 10 meses após o plantio a campo. Para a medição da altura total das plantas, utilizou-se vara graduada em centímetros; para diâmetro do colo, paquímetro digital graduado em milímetros e; para a medição dos diâmetros de copa e posterior cálculo da área de copa, usou-se trena graduada em centímetros, medindo-se dois diâmetros equidistantes $90^{\circ}$ entre si.

Os dados obtidos quanto ao crescimento e vigor foram analisados estatisticamente, comparando-se os níveis de adubação, em arranjo unifatorial 1 (espécie) x 4 (níveis de adubação), em delineamento blocos ao acaso, considerando cada linha dupla como um bloco, perfazendo um total de 4 blocos, sendo que cada bloco (repetição) foi constituída por 10 plantas. Os dados foram analisados no software Assistat v. 7.6 Beta, quanto à análise de regressão (altura, diâmetro do colo e área de copa) e teste de comparação de médias (vigor) visando descrever o desenvolvimento das plantas, quanto as variáveis analisadas, em função das doses de adubação.

\section{Resultados e Discussão}

Sobrevivência das mudas

A taxa de sobrevivência do louro-pardo, após dois meses do plantio, foi de $81,8 \%$, sendo necessária a reposição das mudas. Esta alta mortalidade pode ser explicada em função da fragilidade da muda às condições climáticas, principalmente nos primeiros meses após o plantio. No décimo mês após o plantio a espécie apresentou uma taxa de 97,2\% de sobrevivência, apontando um estabelecimento satisfatório, o que reforça a característica da tendência à pioneira desta espécie.

Em oposição a este resultado, Nieri et al. (2012), ao avaliarem a sobrevivência de 16 espécies florestais nativas em plantio experimental, no município de Dois Vizinhos, $\mathrm{PR}$, após dois meses do plantio, constataram uma porcentagem de sobrevivência de $100 \%$ para o Louro-pardo.

Resultado semelhante ao encontrado no presente trabalho foi constatado por Nicodemo et al. (2009), onde analisou-se o desenvolvimento inicial de outras espécies nativas, para compor um sistema silvipastoril, no município de São Carlos, SP. Na primeira avaliação, 68 dias após o plantio, a canafístula (Peltophorum dubium) encontrava-se com 99\% de sobrevivência e o pau-jacaré (Piptadenia gonoacantha) com 61\%. A sobrevivência acumulada, 334 dias após o plantio, foi de $90 \%$ para a canafístula, seguida do mutambo (Guazuma ulmifolia) com $80 \%$, capixingui (Croton floribundus) com $75 \%$ e angico-branco (Anadenanthera colubrina) com $72 \%$.

Diante disso, pode-se afirmar que louropardo é uma espécie que apresenta boa adaptação quando não afetado por situações adversas, respondendo positivamente aos tratos culturais aplicados, porém pode ter sensibilidade a fatores como estresse hídrico e ocorrência de formigas cortadeiras, ambos fatores que devem ser controlados na implantação e manejo de plantios. 
Crescimento do louro-pardo

A importância da avaliação do diâmetro está no fato de que há uma alta correlação entre a porcentagem de sobrevivência e o diâmetro do colo das mudas, devido à relação positiva entre esse parâmetro e a produção de raízes (OLIVEIRA et al., 2010).

A Figura 1 apresenta os resultados médios de Diâmetro do colo (Dc) para cada tratamento, no período de 10 meses que sucederam o plantio. Na primeira avaliação feita três meses após o plantio, todos os tratamentos apresentaram um Dc médio de aproximadamente $4,50 \mathrm{~mm}$, devido ao curto intervalo de tempo entre a adubação e a avaliação, além da muda encontrar-se na fase de estabelecimento do seu sistema radicular, ainda não diferenciando seu crescimento em função dos tratamentos aplicados.

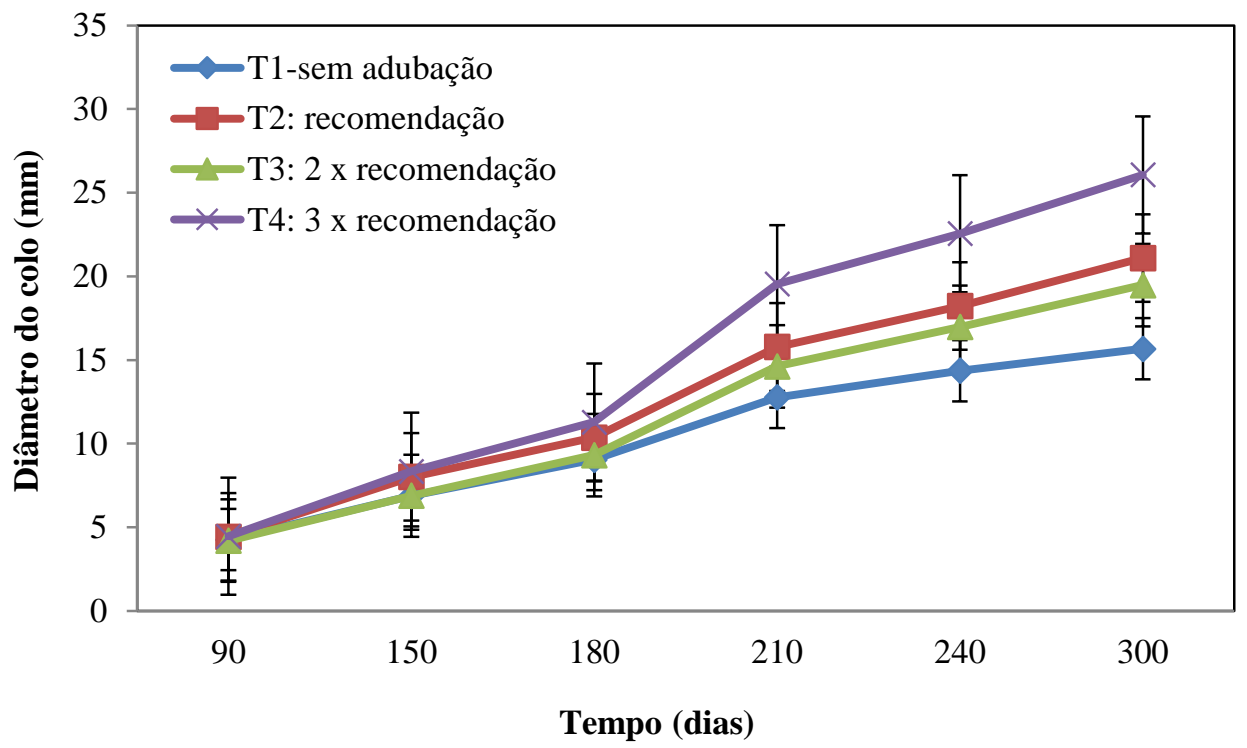

Figura 1: Crescimento em diâmetro do colo das plantas de louro-pardo, em função dos tratamentos, entre o terceiro e o décimo mês após o plantio em sistemas silvipastoril em Dois Vizinhos, PR. * Com base na análise de variância a $95 \%$ de probabilidade, ocorreram diferenças significativas entre os tratamentos a partir da $4^{a}$ avaliação (210 dias). As barras verticais representam o desvio percentual da média. Figure 1: Stem diameter growth of louro-pardo plants, in function of treatments, between the third and tenth month after the plantation in silvopastoral system in Dois Vizinhos-PR. * With base of variance analysis at 95\% of probability, happen significant differences between the treatments from the $4^{\mathrm{a}}$ evaluation ( 210 days). The vertical bars represent the percentage deviation of the average.

Nos meses seguintes, a partir da segunda avaliação, iniciou-se uma diferenciação entre os tratamentos, onde o T4 (o triplo de adubo recomendado) passou a se destacar, atingindo Dc médio de 26,00 mm contra $15,70 \mathrm{~mm}$ do T1 (sem adubação) ao final da avaliação, aos 10 meses. Quanto aos tratamentos 2 e 3, não houve diferença significativa nos resultados entre os mesmos, onde o T2 superou os diâmetros médios do T3 em números absolutos.

O crescimento do louro-pardo em função da adubação, a partir dos 210 dias após o plantio, apresentou comportamento linear e positivo com o aumento da dose de adubo (Figura 2).

No estudo de Biz et al. (2012), analisou-se o crescimento relativo (CR\%) em diâmetro de colo de 16 espécies nativas em plantios puros, com adubação de $360 \mathrm{~g} \mathrm{muda}^{-1}$ com NPK (8-20-10), também em Dois Vizinhos - PR. Entre o segundo e o sétimo mês de implantação, o louropardo apresentou incremento de $259 \%$, onde o diâmetro inicial era de $6,78 \mathrm{~mm}$, atingindo 24,34 $\mathrm{mm}$ na avaliação final, indicando boa adaptação ao local.

Segundo Oliveira et al. (2010), a evolução da altura das mudas, ao longo do processo produtivo, é essencial para a determinação das práticas de condução da floresta, como o controle de pragas e/ou doenças e adubação. 

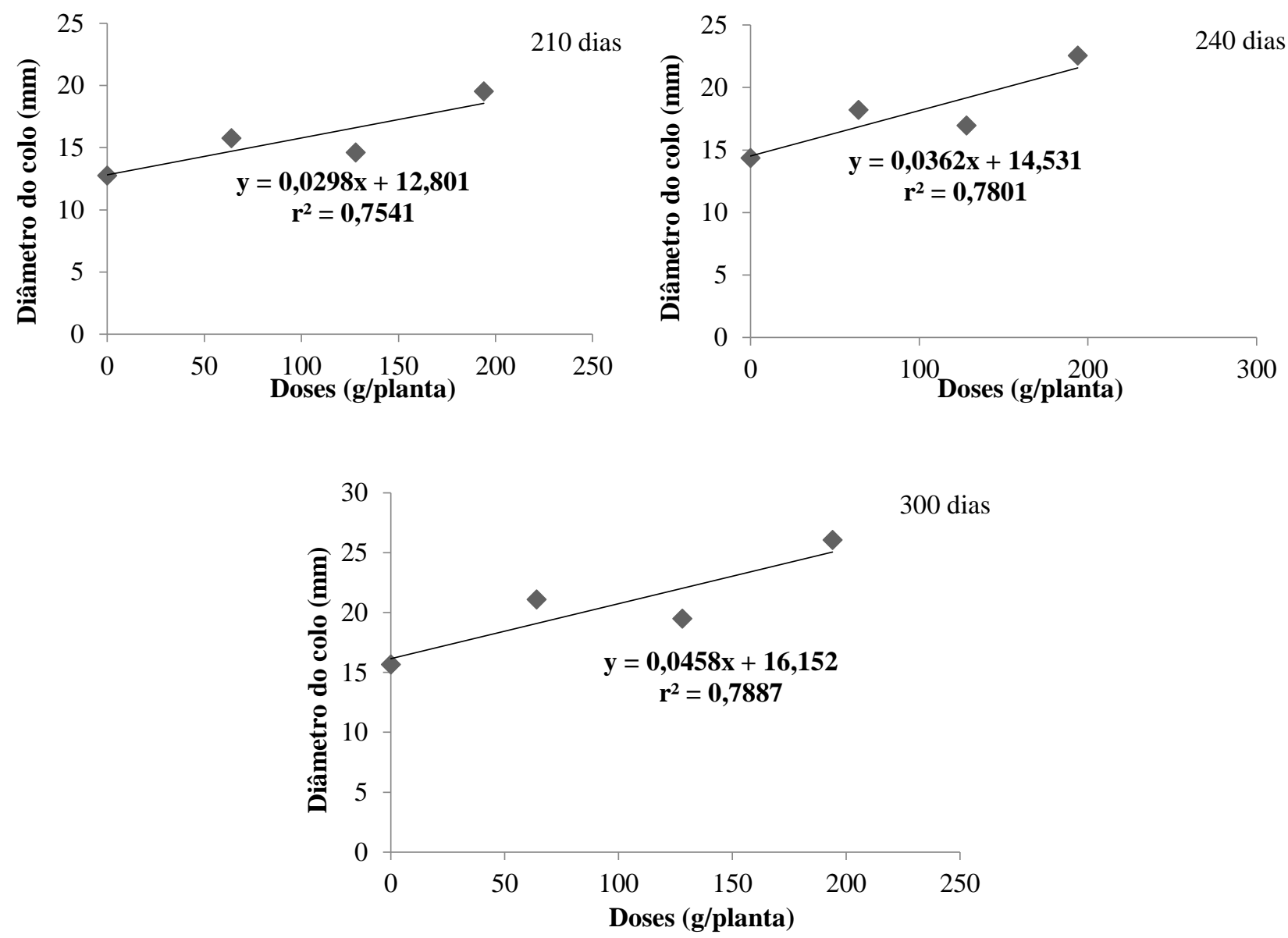

Figura 2: Crescimento em diâmetro do colo (Dc) de plantas de louro-pardo em função de diferentes doses de adubação NPK aos 210, 240 e 300 dias após o plantio em sistema silvipastoril em Dois Vizinhos, PR.

Figure 2: Stem diameter growth of louro-pardo plants in function of different fertilization dosages with NPK in the 210, 240 and 300 days after planting in a silvopastoral system in Dois Vizinhos-PR.

A análise da variação na altura média das plantas de cada tratamento, do terceiro ao décimo mês após o plantio (Figura 3), mostra uma superioridade do T4 sobre os demais tratamentos. Este, se comparado com o T1, apresentou diferença de aproximadamente 23 $\mathrm{cm}$, significativamente superior, assim como o observado para a variável diâmetro do colo.

As plantas submetidas aos tratamentos 2 e 3, responderam de forma semelhante, apontando média de $87 \mathrm{~cm}$ de altura. Estatisticamente, observou-se que a variável altura (Figura 4) respondeu mais rapidamente à adubação em relação ao diâmetro de colo, pois apresentou diferença significativa já no terceiro mês após o plantio, enquanto o Dc somente no quarto mês, caracterizando nitidamente o crescimento inicial em altura e massa foliar como prioritário em relação ao diâmetro do tronco.

A influência da adubação no crescimento de louro-pardo em sistema silvipastoril também foi estudada por Radomski et al. (2012), em plantio na região Sudoeste do Paraná. Os tratamentos estudados, baseados em adubação orgânica (AO - 5 litros de esterco de gado) junto com duas formulações de adubação mineral (100 g de NPK): 5-25-25 (AM1) e 2-25-25 (AM2)), mostraram que, aos cinco anos de idade, a altura média do tratamento $\mathrm{AO}+\mathrm{AM} 1$ foi significativamente superior (CR de 250\%), evidenciando o efeito positivo da combinação "adubação orgânica + adubação mineral". 


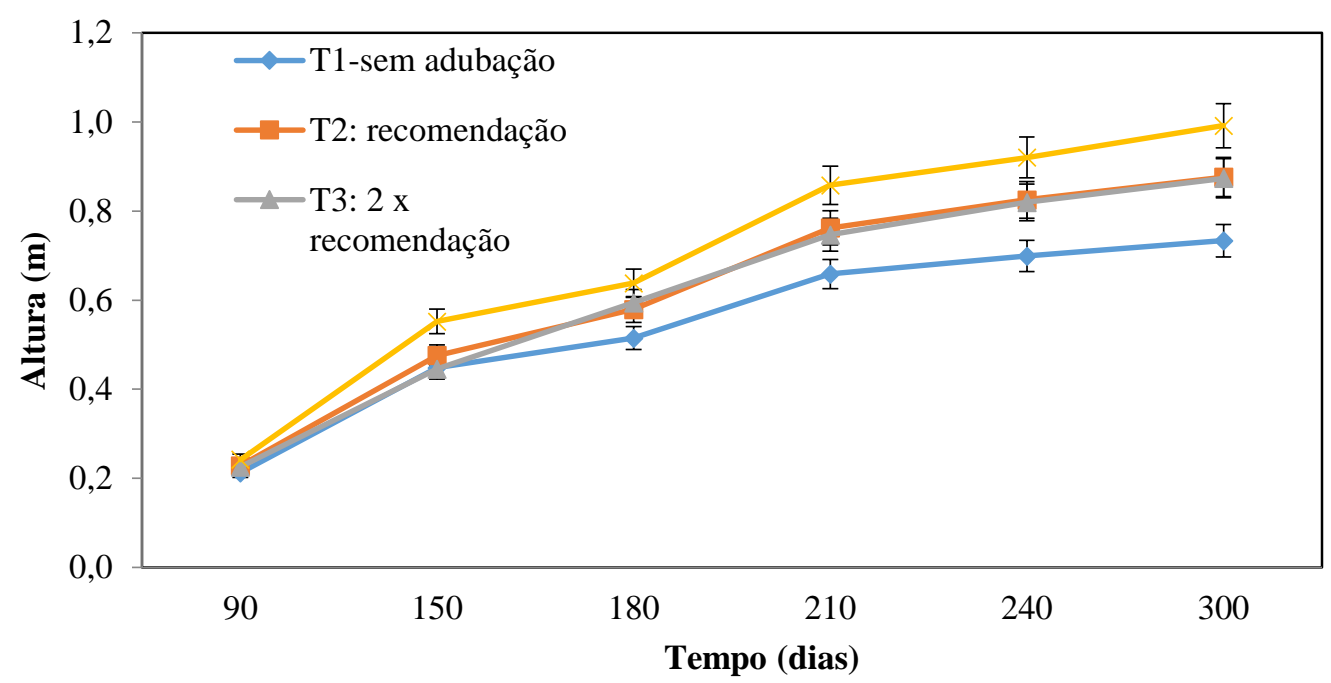

Figura 3: Crescimento em altura das plantas de louro-pardo, em função dos tratamentos, entre o terceiro e o décimo mês após o plantio em sistemas silvipastoril em Dois Vizinhos, PR. *Com base na análise de variância a 95\% de probabilidade, ocorreram diferenças significativas entre os tratamentos a partir da $3^{\mathrm{a}}$ avaliação (180 dias). As barras verticais representam o desvio percentual da média.

Figure 3: Height growth of louro-pardo plants, in function of treatments, between the third and tenth month after the plantation in silvipastoral system in Dois Vizinhos-PR. * With base of variance analysis at 95\% of probability, happen significant differences between the treatments from the $3^{\mathrm{a}}$ evaluation ( 180 days). The vertical bars represent the percentage deviation of the average.
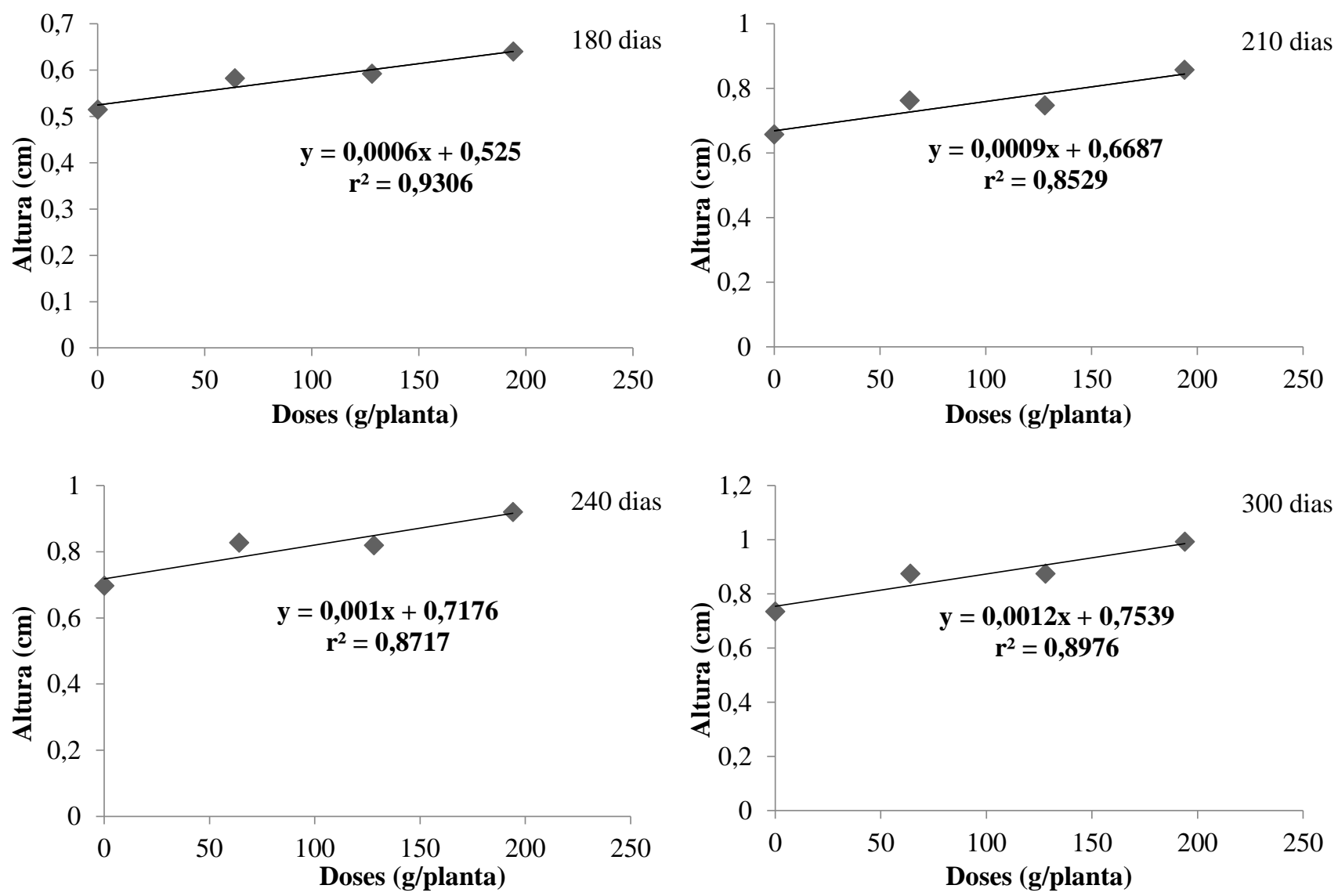

Figura 4: Crescimento em altura $(\mathrm{m})$ de plantas de louro-pardo em função de diferentes doses de adubação NPK aos 180 , 210, 240 e 300 dias após o plantio em sistema silvipastoril em Dois Vizinhos, PR.

Figure 4: Height growth $(\mathrm{m})$ of louro-pardo plants in function of different fertilization dosages with NPK in the 180, 210, 240 and 300 days after planting in a silvopastoral system in Dois Vizinhos-PR. 
No presente estudo, o efeito da adubação mineral elevada (3 x a recomendação da análise de solo) também causou um crescimento elevado (CR de 312,5\% aos 10 meses de idade), enfatizando o efeito positivo da adubação para a espécie, independentemente do tipo de fertilizante ou idade de avaliação.

Em experimento conduzido por Bertolini et al. (2012), avaliando o crescimento de plantios puros de 16 espécies nativas no Paraná, o Louropardo apresentou crescimento relativo em altura, do segundo ao sétimo mês após o plantio, de $396,4 \%$, variando de $0,28 \mathrm{~m}$ para $1,39 \mathrm{~m}$, respectivamente, tendo sido adubado com $360 \mathrm{~g}$ de NPK 08-20-10 por planta, dois meses após o plantio, tendo sido uma das espécies nativas plantadas que maior resposta apresentou à adubação.

$\mathrm{Na}$ comparação entre os tratamentos, verificou-se a maior resposta no T4, para a variável área de copa (Figura 5), confirmando que o Louro-pardo responde melhor a maiores níveis de adubação tanto para diâmetro do colo e altura quanto para área de copa.

A partir da quarta avaliação, a área de copa das árvores que receberam o triplo da dose de adubação mostrou uma média de aproximadamente $0,34 \mathrm{~m}^{2}$, enquanto as mudas que não receberam adubação possuíam apenas $0,12 \mathrm{~m}^{2}$ de área de copa.

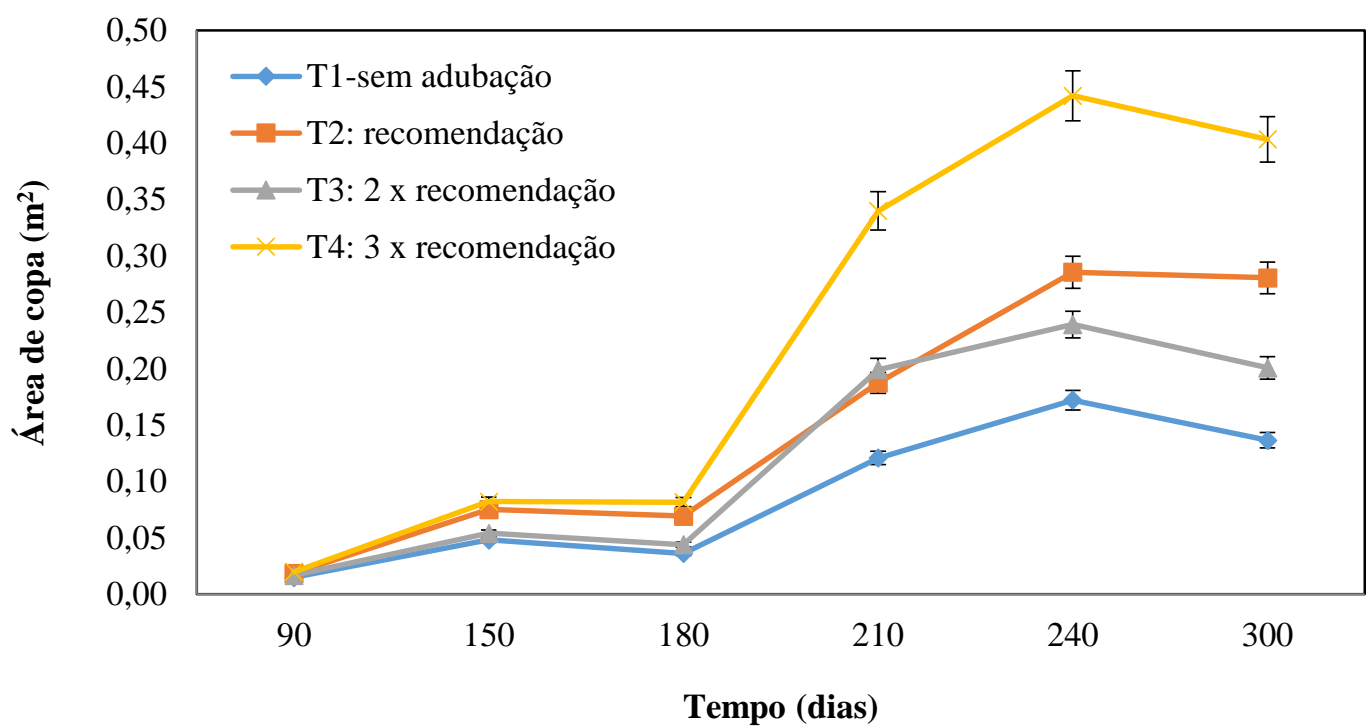

Figura 5:Crescimento em área de copa $\left(\mathrm{m}^{2}\right.$ planta $\left.{ }^{-1}\right)$ do louro-pardo, em função dos tratamentos, entre o terceiro e o décimo mês após o plantio em sistemas silvipastoril em Dois Vizinhos, PR. * Com base na análise de variância a $95 \%$ de probabilidade, ocorreram diferenças significativas entre os tratamentos a partir da $4^{\mathrm{a}}$ avaliação (210 dias). As barras verticais representam o desvio percentual da média.

Figure 5: Crown area growth of louro-pardo $\left(\mathrm{m}^{2}\right.$ plant $\left.{ }^{-1}\right)$, in function of treatments, between the third and tenth month after the plantation in silvipastoral system in Dois Vizinhos-PR. *With base of variance analysis at $95 \%$ of probability, happen significant differences between the treatments from the $4^{\mathrm{a}}$ evaluation (210 days). The vertical bars represent the percentage deviation of the average.

Entre o oitavo e o décimo mês, houve redução na área de copa para todos os tratamentos, fato considerado normal por se tratar de uma planta caducifólia e a última avaliação coincidir com o período de inverno, com caducidade foliar dos exemplares ocorrendo e diminuindo, consequentemente, a área de copa (Figura 6).

Segundo Abaurre (2009), a área de copa é proporcional ao espaçamento, apresentando áreas maiores em espaços mais amplos, provavelmente devido à maior disponibilidade de recursos ambientais, sobretudo luminosidade. Isso explica o fato dos sistemas silvipastoris apresentarem árvores com área de copa ampla.

Ludvichak et al. (2012) analisaram a área de copa em 16 espécies nativas plantadas em Dois Vizinhos - PR, em que o louro-pardo apresentou uma taxa de crescimento relativo de $390,5 \%$ aos sete meses de idade, diferindo consideravelmente do resultado aqui encontrado, que foi de $1351,1 \%$, aos 10 meses. 

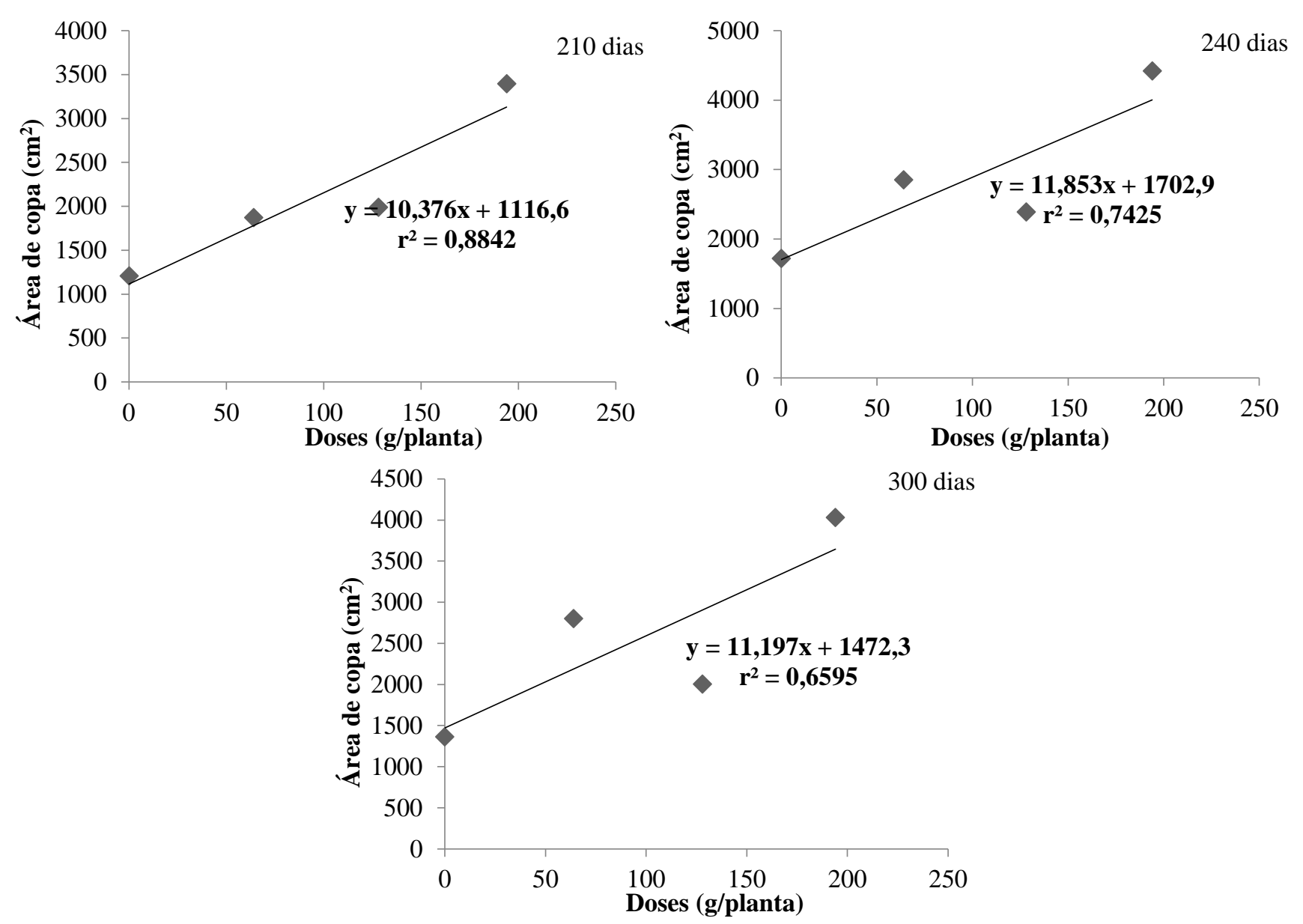

Figura 6: Crescimento de plantas de louro-pardo em área de copa $\left(\mathrm{cm}^{2}\right.$ planta $\left.^{-1}\right)$ em função de diferentes doses de adubação NPK aos 210, 240 e 300 dias após o plantio em sistema silvipastoril em Dois Vizinhos, PR.

Figure 6: Louro-pardo plant growth in crown area $\left(\mathrm{cm}^{2}\right.$ plant $\left.{ }^{-1}\right)$ in function of different fertilization doses with NPK in the 210, 240 and 300 days after planting in a silvopastoral system in Dois Vizinhos-PR.

Assim como os resultados encontrados para louro-pardo, espécies do gênero Eucalyptus sp. também mostram respostas positivas a doses elevadas de fertilização. Em trabalho realizado por Menegassi et al. (2012) com plântulas de Eucalyptus citriodora, E. dunnii e E. grandis, em resposta a diferentes fontes (de liberação rápida (NPK 6-30-06) e lenta (osmocote NPK 18-06-12)) e doses $\left(0,0 ; 2,5 ; 5,0\right.$ e 7,5 $\mathrm{kg} \mathrm{m}^{-3} \mathrm{de}$ substrato) de adubação, encontrou-se resposta significativa para os efeitos de adubação e doses em todos os caracteres avaliados, sendo o Osmocote que promoveu os maiores resultados em crescimento na dose de $7,5 \mathrm{~kg} \mathrm{~m}^{-3}$.

Análise qualitativa

Macedo et al. (2002) consideram que o potencial de estabelecimento de espécies florestais é expresso pela capacidade de adaptação e o vigor das mudas, frente às reais condições ecológicas observadas no campo. Ao longo do tempo, o vigor mostra o desenvolvimento adequado das mudas e sua qualidade, podendo ser afetado por estresse hídrico, ataque de pragas ou doenças e danos físicos ocorridos. Neste sentido, umas das variáveis analisadas, durante o período de 10 meses, nas plantas de louro-pardo, foi o vigor (Tabela 2).

Na primeira avaliação de vigor, aos 3 meses após o plantio a campo, a maior parte das plantas apresentava vigor alto (50 a $62,5 \%$ das plantas) e médio (32,5 a 45\%), contra valores entre 5 e $7,5 \%$ para vigor baixo, com frequências significativamente inferiores. Aos 10 meses, 
essa situação se alterou, ainda com o vigor médio sendo predominante, mas com elevação na frequência de plantas com baixo vigor em detrimento do alto.

Tabela 2: Frequência relativa do vigor das plantas de louro-pardo aos 3 e 10 meses após o plantio em sistema silvipastoril implantado em Dois Vizinhos-PR para cada tratamento de adubação.

Table 2: Relative Frequency of louro-pardo plant vigor to the 3 and 10 months after planting in silvopastoral system in Dois Vizinhos-PR, for each fertilizer treatment.

\begin{tabular}{|c|c|c|c|c|c|c|c|c|}
\hline \multirow{2}{*}{ Vigor } & \multicolumn{4}{|c|}{3 meses (Dez/2013) } & \multicolumn{4}{|c|}{10 meses (Jul/2014) } \\
\hline & T1 & $\mathbf{T 2}$ & T3 & T4 & T1 & $\mathbf{T 2}$ & T3 & T4 \\
\hline 1: alto & $50,0 \mathrm{aA}$ & $55,0 \mathrm{aA}$ & $62,5 \mathrm{aA}$ & $52,5 \mathrm{aA}$ & $23,7 \mathrm{bB}$ & $28,2 \mathrm{bB}$ & $30,7 \mathrm{bB}$ & $16,2 \mathrm{bB}$ \\
\hline 2: médio & $45,0 \mathrm{aA}$ & $37,5 \mathrm{bB}$ & $32,5 \mathrm{bB}$ & $42,5 \mathrm{aB}$ & $42,1 \mathrm{aA}$ & $48,7 \mathrm{aA}$ & $51,3 \mathrm{aA}$ & $64,9 \mathrm{aA}$ \\
\hline 3: baixo & $5,0 \mathrm{bB}$ & $7,5 \mathrm{cB}$ & $5,0 \mathrm{cB}$ & $5,0 \mathrm{bB}$ & $34,2 \mathrm{abA}$ & $23,1 \mathrm{bA}$ & $18,0 \mathrm{cA}$ & $18,9 \mathrm{bB}$ \\
\hline
\end{tabular}

Essa situação ocorreu em todos os tratamentos, com queda significativa na frequência do vigor alto e elevação na do baixo, com menor variação apenas na frequência do vigor médio. No entendimento do processo, com base nas avaliações e observações in loco, podese perceber que plantas que, na avaliação dos três meses estavam com vigor médio passaram a apresentar vigor baixo e plantas que estavam com vigor alto passaram a médio e baixo, nas devidas proporções de cada tratamento, evidenciando um declínio geral de vigor das plantas entre as duas avaliações.

Apesar das variações ocorridas, as doses de adubação pouco ou nada influenciaram no vigor geral das plantas, fato que mostra que a adubação, apesar de causar melhoria no crescimento das plantas, com base nas variáveis quantitativas, não foi capaz de tornar as plantas suficientemente rústicas a ponto de suportarem eventuais efeitos ambientais adversos até a idade avaliada.

Um dos problemas ambientais ocorridos no decorrer do experimento foi a ocorrência de uma bacteriose foliar nas plantas de louro-pardo nos meses que antecederam o inverno (abril e maio). Após detecção em campo de um significativo percentual de folhas com manchas escuras e processo acentuado de abscisão foliar, amostras das mesmas foram coletadas e, posteriormente, analisadas no Laboratório de Fitossanidade da UTFPR Câmpus Dois Vizinhos, identificandose, com base na análise dos especialistas do citado laboratório, tratar-se de uma bacteriose.

Os sintomas apresentados pelas plantas atacadas pela bacteriose foram abscisão foliar, infecções iniciais pelos hidatódios, translocação pelas nervuras e corrimento de bactérias observado próximo ao tecido foliar da planta. Para identificação específica da bactéria causadora de tais danos, o estudo demanda de um tempo maior, pois não foram encontrados relatos na literatura científica sobre tal infecção para a espécie.

Outras espécies florestais vêm sendo atacadas por enfermidades de origem bacteriana, como é o caso de Eucalyptus sp. Segundo Auer et al. (2011), desde 2009 estão ocorrendo registros de ataques frequentes de bactérias em mudas e árvores jovens de eucalipto. Os autores ainda ressaltam que, comparada com outras doenças em eucalipto, a bacteriose em folhas possui registro recente, tornando sua diagnose uma atividade complexa, como é o caso presenciado no povoamento de louro-pardo em questão.

Além dos sintomas descritos, a mancha foliar 
bacteriana diminui a área fotossintética das folhas na planta, isso ocasiona intensa desfolha, resultando na desaceleração no crescimento das mudas, que ficam debilitadas e, portanto, perdem sua vigorosidade (NEVES, 2007).

Ainda deve-se considerar o fato da última avaliação qualitativa ter ocorrido no período de inverno, época em que a espécie estudada perde suas folhas, afetando naturalmente o vigor das mudas.

\section{Conclusões}

As mudas de Cordia trichotoma implantadas sob diferentes níveis de adubação, em sistema silvipastoril, apresentaram crescimento relativo médio de $374,2 \%$ em diâmetro do colo, 278,3\% em altura, e 1351,1\% em área de copa, no período de 10 meses. $\mathrm{O}$ vigor qualitativo não foi influenciado pela adubação e sim pela ocorrência de bacteriose e a coincidência com o período de inverno, com a caducidade natural das folhas. A aplicação de $192 \mathrm{~g} \mathrm{planta}^{-1}$ de NPK, que representa o triplo da recomendação para eucalipto, pode ser usada para o louropardo, pois foi a que promoveu os maiores resultados de crescimento em altura, diâmetro do colo e área de copa para a espécie até os 300 dias de idade a campo.

\section{Referências}

ABAURRE, G. W. Crescimento de espécies florestais pioneiras e não pioneiras sob diferentes espaçamentos em plantio de recomposição florestal. 2009. 16f. Trabalho de Conclusão de Curso (Graduação em Engenharia Florestal). Universidade Federal Rural do Rio de Janeiro, Seropédica, 2009.

ALVARES, C. A. et al. Koppen's climate classification map for Brazil. Meteorologische Zeitschrift, Stuttgart, Alemanha, v. 22 n. 6, p. 711-728, 2013.

AUER, C. G.; SANTOS, Á. F.; RODRIGUES
NETO J. Mancha foliar bacteriana em plantios de eucalipto na região Sul do Brasil. (Comunicado Técnico n. 269) EMBRAPA. Colombo, 2011, 3 p.

BALBINO, L. C. et al. Evolução tecnológica e arranjos produtivos de sistemas de integração lavoura-pecuária-floresta no Brasil. Pesquisa Agropecuária Brasileira, v. 46, n. 10, 2011.

BERTOLINI, Í. C. et al. Crescimento inicial em altura de 16 espécies florestais nativas plantadas na região sudoeste do Paraná. In: CONGRESSO FLORESTAL PARANAENSE, 4, 2012, Curitiba. Anais Eletrônicos... Disponível em: http://www.congressoflorestalpr.com.br/conteu do.php?id=75. Acesso em: 30 jul. 2014.

BIZ, S. et al. Crescimento inicial em diâmetro de colo de espécies florestais nativas madeireiras plantadas em Dois Vizinhos-PR. In: CONGRESSO FLORESTAL PARANAENSE, 4., 2012, Curitiba. Anais Eletrônicos... Disponível em: http://www.congressoflorestalpr.com.br/conteu do.php?id=75. Acesso em: 14 nov. 2014.

CARVALHO, M. M. Contribuição dos sistemas silvipastoris para a sustentabilidade da atividade leiteira. In: SUSTENTABILIDADE DE SISTEMAS DE PRODUÇÃO DE LEITE A PASTO E EM CONFINAMENTO, 3., 2001, Juiz de Fora, Anais... Juiz de Fora, 2001 p. 85108.

EMBRAPA - Empresa Brasileira de Pesquisa Agropecuária. Sistema brasileiro de classificação de solos. 3 ed. Rio de Janeiro: EMBRAPA SOLOS, 2013, 353 p.

IBGE - INSTITUTO BRASILEIRO DE GEOGRAFIA E ESTATÍSTICA. Mapa de vegetação do Brasil. Brasília: IBGE, 2004.

IAPAR - INSTITUTO AGRONÔMICO DO PARANÁ. Cartas Climáticas do Paraná. Disponível em: <http://www.iapar.br/modules/conteudo/conteu 
do.php?conteudo=677> Acesso em: 12 nov. 2013. Londrina, PR, 2000.

LUDVICHAK, A. A. et al. Comportamento inicial da área de copa de espécies nativas do paraná em plantio homogêneo. In: CONGRESSO FLORESTAL PARANAENSE, 4., 2012, Curitiba. Anais Eletrônicos... Disponível em: <http://www.congressoflorestalpr.com.br/conte udo.php?id=75> Acesso em: 29 jul. 2014.

MACEDO, R. L. G. et al. Dinâmica de estabelecimento de Tectona grandis L.f. (Teca) introduzida em cafezal na região de Lavras Minas Gerais. Brasil Florestal, n. 73, p. 31-38, 2002.

MENEGASSI, A. D. et al. Produção de mudas de eucalipto sob diferentes fontes de adubação. In: CONGRESSO FLORESTAL PARANAENSE, 4., 2012, Curitiba. Anais Eletrônicos... Disponível em: < http://malinovski.com.br/CongressoFlorestal/Tr abalhos/05-Silvicultura/SIL-Artigo-26.pdf> Acesso em: 26 jul. 2014.

NEVES, D. A. Condições favoráveis à mancha foliar causada por Xanthomonas axonopodis em eucalipto. 2007. 22 f. Dissertação (Mestrado em Fitopatologia) - Universidade Federal de Viçosa, Viçosa, MG, 2007.

NICODEMO, M. L. F. et al. Desenvolvimento inicial de espécies florestais em sistema silvipastoril na região Sudeste. Pesquisa Florestal Brasileira, n.60, p. 89-92, 2009.

NIERI, E. M. et al. Ocorrência e evolução da sobrevivência e tortuosidade do tronco de espécies nativas plantadas em Dois VizinhosPR. In: CONGRESSO FLORESTAL PARANAENSE, 4., 2012, Curitiba. Anais Eletrônicos... Disponível em: http://www.congressoflorestalpr.com.br/conteu do.php?id=75. Acesso em: 25 jul. 2014.
DAVIDE, A. C. Desenvolvimento de mudas de ipê branco, açoita cavalo, ipê roxo, caroba e vinhático em viveiro. In: CONGRESSO DE PÓS-GRADUAÇÃO DA UFLA, 19., 2010, Lavras. Anais eletrônicos... Disponível em: <http://www.sbpcnet.org.br/livro/lavras/resumo s/411.pdf > Acesso em: 23 ju.1 2014.

RADOMSKI, M. I.; SILVA, V. P.; CARDOSO, D. J. Crescimento de Louro-pardo (Cordia trichotoma (Vell.) Arráb. Ex Steud.) em sistema agrossilvipastoril. In: CONGRESSO LATINOAMERICANO DE SISTEMAS AGROFLORESTAIS PARA A PRODUÇÃO PECUÁRIA SUSTENTÁVEL, 7., 2012, Belém. Anais eletrônicos... Disponível em: <http://ainfo.cnptia.embrapa.br/digital/bitstrea m/item/71891/1/2012-M.Izabel-CLSAPPS-

Crescime nto.pdf> Acesso em: 12 nov. 2013.

SBCS-CQFS - SOCIEDADE BRASILEIRA DE CIÊNCIA DO SOLO - COMISSÃO DE QUÍMICA E FERTILIDADE DO SOLO. Manual de Adubação e de Calagem para os Estados do Rio Grande do Sul e de Santa Catarina. Comissão de Química e Fertilidade do Solo. - 10. ed. - Porto Alegre, 2004.

OLIVEIRA, G. N.; TEIXEIRA, L. A. F.; 